\title{
Challenges and Opportunities of IDTV for audience measurement systems: a set-top box based approach
}

\author{
Katrien Berte ${ }^{1}$, Philip Leroux ${ }^{2}$, Lieven De Marez ${ }^{1}$, Els De Bens ${ }^{1}$, Filip De Turck ${ }^{2}$ \\ ${ }^{1}$ MICT-IBBT, Department of Communication Sciences, Ghent Universtiy. \\ ${ }^{2}$ IBCN-IBBT, Department of Information Technology, Ghent University.
}

\begin{abstract}
Advanced innovations such as digital, interactive transmission technologies and PVRs have changed TV viewing behavior. Digital television has widened the range of channels for advertisers, entailing sweeping shifts in marketing budget allocations from traditional media to interactive and personalized media. In order to maintain their position as the world's largest advertising channel, television broadcasters are highly dependent on accurate and in-depth audience data. Unfortunately, the traditional measurement techniques fail to keep up with innovations in television.

This paper reflects on the current state of audience measurement in Europe and describes our search to tackle some of the challenges of the interactive, digital broadcasting market. As this paper is the result of a multidisciplinary approach, it reflects both on expert user requirements as well as on technical requirements of a next generation audience measurement system. Contrary to traditional systems which use dedicated and expensive hardware, this paper presents a set-top box-only approach.
\end{abstract}

\section{Keywords}

Interactive advertising, digital television, audience measurement, personalization.

\section{Introduction}

Traditional advertising and media markets are going through radical changes. The advances of digital media have distorted the sound relations between all the stakeholders in this economical sector (Cappo 2005, Jaffe 2005, McQuail 2005). Several innovations have widened the range of channels for advertisers, entailing sweeping shifts in marketing budget allocations (Wilbur 2008). New media, such as the internet, interactive digital television (iDTV) and mobile devices, which allow for more personalized and direct response advertising, are gaining in importance and are grasping a bigger share of the advertising revenues at the expense of the mass media which are highly dependent on these advertising revenues (Carat 2005, 2006, De Bens \& Raeymaeckers 2007, Doyle 2002).

In comparison with other media, Television is mostly affected by these developments. The fragmentation of the audience has major consequences for the broadcasters' advertising revenue streams (Lyle 2008, Picard 2003). Due to the rising complexity of the sector, advertising space should be purchased using planning software in order to select the most interesting channels to grasp the attention of the audience (Lyle 2008, Schultz 2006, Schultz, et al., 2006, Wilbur 2008). Due to the growing amount of clutter, the efficiency of the 30 second spot is often questioned by advertisers (Ahonen \& More 2005, Jaffe 2005). The very nature of the broadcasting market, selling eyeballs to advertisers (meaning access to audiences), is challenged by several innovations such as time-shifted and on demand viewing, therefore, the traditional business model of free audiovisual content financed by ad revenues is severely questioned by all stakeholders (De Bens \& Mazzoleni 1998). 
In order to maintain its position as the largest and most authoritative advertising medium, television has to bend these challenges into opportunities and is therefore increasingly dependent on detailed and up to date information regarding the size and the profile of their audiences. Therefore, audience research and rating analysis become increasingly important. According to Buzzard (2002: 275), audience research 'provides the institutional data used for the sale of advertising time - the economic base for both the broadcast and cable industry', emphasizing the importance of accurate audience data in the business model of the broadcasting industry. Based on these data, the pricing of TV advertising space is set and access to attractive consumers segments is sold to advertisers. Their spending can be reinvested in the production of qualitative content which can again be used to attract more viewers, a practice often referred to as the vicious cycle of network television (Doyle 2002: 62, Jaffe 2005: 23).

Although television is currently one of the best measurable mass media in Europe, audience data and ratings have not always been this important to broadcasters (Urban 2008, Otten 2006). In the early years of television, the European broadcasting landscape was dominated by the monopolies of national public broadcasters. Due to the limited amount of available frequencies, it was technologically impossible to offer a wide range of channels to the audiences (Ellis 2000, Siune \& Hulten 1998). National governments were controlling the spectrum which was strictly regulated (Brandts \& De Bens 2000). As there was no competition in the market and advertising was strictly limited, there was little or no need for audience data or ratings.

Nevertheless, the old order, as McQuail (2005) describes this era of scarcity and government monopoly, started to stagger in the early 80's. New transmission technologies such as cable and satellite transformed the broadcast market into an era of availability (Ellis 2000, McQuail 1995, 1998, Wieten, et al., 2000). These technologies offered several opportunities to broadcast more stations, to reach larger regions and to work for cheaper rates. Therefore, the monopoly of the public broadcasters could no longer be supported so markets were opened up to private broadcasters (McQuail 1995). Additionally, several European countries witnessed a climate of deregulation in other areas due to the changing political and societal climate. The deregulation led to the commercialisation of broadcasting as the state controlled government monopoly of the public broadcasters was replaced by a dual broadcasting system characterized by the presence of both public and private broadcasters (Bardoel \& D'Haenens 2008, Brandts \& De Bens 2000, Dahlgren 2000, Sinclair 2004, Siune \& Hulten 1998, Siune 1998). The business model of private broadcasters was solely based on advertising revenues. New national and international competitors entered the broadcasting market, slowly fragmenting the viewers into these different channels. Broadcasters became more and more reliant on audience measurement systems and the efforts of several research companies lead to the development of the 'people meter', a measuring device directly connected to the television set which is still being used in Europe today (Bermejo 2009, Buzzard 2002). Additionally, several subscription based broadcasters entered the market generating revenues directly from viewers. Originally, it was not permitted to use a combined approach generating both revenues from advertisers as well as viewers, so these channels were not willing to invest in audience measurement systems (Nolan 1997). 
Ellis (2000) identified a third era in the history of broadcasting, the era of plenty, which started with several technological advances in the production and the distribution of audiovisual content. Due to new, digital transmission technologies like DVB-T, DVB-C, DVB-H, DVB-S and digital compression techniques it is possible to broadcast even more channels using different devices, a trend which is often described as divergence (De Marez, et al., 2008, Seabright, et al., 2007, Urban 2008, Cauberghe \& De Pelsmacker 2006, Musschoot \& Lombaerts 2008, Negroponte 1995). The classical fixed television set is also challenged by new media such as the internet and mobile devices but has also transformed its appearance and picture quality (Musschoot \& Lombaerts 2008). Digitalization blurs the boundaries between the different media and reinforces existing trends of commercialization and the fragmentation of the audience.

In this era of plenty, the availability of accurate data on viewing behavior is of the utmost importance for the commercialization of television channels. Commercial broadcasters determine the pricing of their advertising space based on reach and viewer profile, while public service broadcasters are dependent on audience ratings for the evaluation of their public assignment. Despite this large dependence on audience information, traditional measurement techniques fail to keep up with the advancements in digital television (Napoli 2001). The fragmentation of the audience, changes in media usage, the arrival of new media and ad avoidance techniques challenge the traditional audiometric practices. Due to the increasing popularity of time shifting and VOD services, scheduled viewing in prime time has been partly transformed to on demand viewing. Using the technology of the PVR, viewers can fast forward and skip commercials.

Viewing behavior is clearly changing, confronting audience measurement with new challenges and opportunities. What are the implications for the traditional audience measurement systems? What are the expectations of commercial television channels, advertisers, professional advertising and communication agencies with regard to the measurement of audiovisual content on digital and mobile screens? Which are the most likely challenges and which scenarios can be identified for new IDTV audience measurement systems? And how can they be tackled technologically?

\section{Methodology}

The research in this paper is part of a larger research project, Stimulating Consumer Data (SKODA), conducted for Belgacom, one of the major telecom providers in Belgium. The research was conducted by an interdisciplinary group of researchers from the department of Communication Sciences and the department of Information Technologies of Ghent University who joined forces as part of the Interdisciplinary Institute for BroadBand Technology (IBBT).

Both research groups worked together in order to develop several scenarios for an advanced audience measurement system tailored to the interactive and digital future of television broadcasting in Belgium. In order to ensure the development of a better system, the standard methodologies for audience measurement were studied. Not only existing methodologies were inventoried, current experimental methodologies were also studied.

In addition to this state of the art research, several expert interviews were conducted in order to get some insight into their current practices and future requirements. Although the state of the art research mostly focuses on the European measurement system, mostly Belgian advertisers were interviewed. 
Five types of expert users were identified and questioned using a qualitative research design. Firstly, 35 interviews with Belgian advertisers were conducted. Secondly, most Flemish broadcasters were questioned. Thirdly, professional support agencies such as an advertising agency and media planning agency were also part of the research. Thirdly, we also questioned a rather new but already very influential market player, the telecom providers which are becoming increasingly important due to their power to control the access of a broadcaster to the audiences. Finally, three foreign experts from Arbitron, Nielsen Media Research and Turner Broadcasting System were also questioned. Based on these three interviews, we were able to compare the current European audience measurement system to American audience measurement systems and the Portable People Meter, a portable, innovative technique to perform audience research. Based on these interviews we concluded that Belgium is one of the most advanced countries, worldwide and even in Europe, with regard to audience measurement. This conclusion combined with the dominance of DVB-C and IPTV for digital TV transmission, the current situation of our market could therefore serve as a test market for next generation audience measurement systems.

\begin{tabular}{|c|c|c|c|}
\hline \multicolumn{4}{|l|}{ Advertisers } \\
\hline Belgacom & De Nationale Loterij & $\mathrm{KBC}$ & Selor \\
\hline Belgisch leger & Delhaize & Luminus & Sony \\
\hline Brantano & Elektrabel & Microsoft & Telenet \\
\hline Carrefour & $\begin{array}{l}\text { Governmental service of Health, Food safety \& } \\
\text { Environment }\end{array}$ & O'Neill Belgium & Toerisme Vlaanderen \\
\hline CocaCola & Henkel & Omega Pharma & Torfs \\
\hline Colruyt & Het Laatste Nieuws & Pepsico & Universal Music \\
\hline D'ieteren & Het Nieuwsblad & Peugeot & Vmma \\
\hline Danone-Lu & HP & Rabobank & Vooruit \\
\hline De Lijn & Inbev & Sara Lee & \\
\hline \multicolumn{4}{|l|}{ Broadcasters } \\
\hline VMMa & SBS Belgium & Kanaal Z & Concentra Media \\
\hline Vitaya & VRT & MTV Networks Belgium & 8 \\
\hline \multicolumn{4}{|l|}{ Advertising agency } \\
\hline \multicolumn{4}{|l|}{ Saatchi \& Saatchi } \\
\hline \multicolumn{4}{|l|}{ Media agency } \\
\hline Aegis Media Group Belgium & $\mathrm{OMD}$ & Space & \\
\hline \multicolumn{4}{|l|}{ TV sales agencies } \\
\hline RMB & VAR & & \\
\hline \multicolumn{4}{|l|}{ Providers } \\
\hline Telenet Digital TV & Belgacom TV & & \\
\hline \multicolumn{4}{|l|}{ Foreign experts } \\
\hline Arbitron & Turner Broadcasting System Inc & Nielsen Media research & \\
\hline
\end{tabular}

\section{Table 1: Participants in the expert interviews}

These 54 interviews were conducted between spring 2008 and spring 2009. As the results were processed, the model of a set-top box based measurement approach was refined and was continuously being evaluated by the experts. This paper presents the challenges of a set-top box-only audience measurement approach, a scenario which was selected based on the findings of the expert user research.

As this paper is the result of a multidisciplinary approach, it also reflects on the technical challenges which are imposed to the development of new measurement systems in order to cope with the current and future advancements in the digital television environment. 


\section{Results: the development of a set-op-box based measurement approach}

\section{State of the art research: Current audience measurement systems}

The audience measurement market in Europe is characterised by a vigorous concentration of research companies. This oligopoly is dominated by three major enterprises: GFK (Gesellschaft für Konsumforschung), AGB Nielsen Media and TNS (Taylor Nelson Sofres), which consist of several local departments. These companies provide software and hardware as well as consulting services to local broadcasters (Peeters, et al., 2005).

In several European countries, these companies act as subcontractors for independent trade organizations such as the Centre for Information on the Media (CIM) in Belgium or BARB in the United Kingdom, while in other countries such as the USA, they have final responsibility for the publication of audience ratings. Most European countries utilize the same methodology although local aspects (f.e. transmission technologies) are taken into account for each separate market. 32 of 43 European Countries use a people meter to measure the viewing behavior while others (mostly Eastern European countries) use diaries or conduct surveys by telephone. In several small and less wealthy countries, there is no audience data available (Peeters, et al., 2005). The people meter can be described as dedicated hardware, an additional box connected to a fixed television set, which registers the viewing behavior of a household on an individual level. Both viewer data and content information are automatically sent over night to the selected research company.

All audience research in Europe is based on a panel approach. Panel members are selected based on a large reference study describing the national population of television viewers. The use of dedicated hardware is very expensive and maintaining the viewer panel in order to guarantee the representativeness is very time consuming.

In addition to the monitoring of viewing behavior, television content, programs as well as ads, is registered in an external database. This practice is often referred to as time logging. The combination of viewer data and time logging data provides advertisers and media agencies with crucial information on the viewing behavior of their target groups and is therefore the foundation of the planning schedule of most television advertising campaigns. The data is also used to provide information on the reach of commercials so advertisers supported by their media agencies, can accurately track the results of their campaigns and adjust them if necessary.

State of the art research: Traditional measurement approach challenged by digital technologies

The arrival of new digital technologies challenges this traditional approach. Several new digital broadcasting technologies have a return path, a new way of connecting viewers directly to broadcasters using nothing but their remote control. On demand viewing and time shifting allow users more freedom to compose their own broadcasting schedule. Interactivity and non linear viewing are not incorporated in the traditional audience measurement practices. As these practices will continue to be adopted by more viewers in the near future, viewing rates based on live viewing practices will decline leaving less attractive figures for broadcasters to present to advertisers.

Regarding the measurement of time shifted viewing, most audience research organizations are currently adopting a new technology. Using the Enhanced Audio Matching (EAM) technique, delayed viewing can also be added to the ratings. The EAM technique compares the audio 
signal of the broadcaster to a reference site. This technique offers the possibility to process the audio signal very quickly therefore allowing the people meter to recognize programmes up to six days after the live broadcast. Several countries such as Belgium, the UK and the Netherlands, adopted the Enhanced Audio Matching (EAM) technique in 2007 (de Vos \& Appel 2007) .

The methodology described here is the Belgian approach to the processing of data from timeshifted viewing. This approach is quite similar to the Netherlands. The idea behind this methodology is derived from research which shows that viewers normally watch a recorded programme very quickly after its live broadcast. Experts therefore make a distinction between three types of television viewing, live viewing, Near live viewing (NLV) and Viewing On The Same Day As Live (VOSDAL). Near live viewing is viewing on the same day as the live broadcast but with several minutes or hours delay. Depending on the type of set-top box, viewers can pause and rewind the live broadcast stream up to three hours of viewing history. On the other hand, viewing on the same day as live or VOSDAL requires the recording of the live program on the hard drive of the set-top box or buying it in the VOD section of the broadcaster.

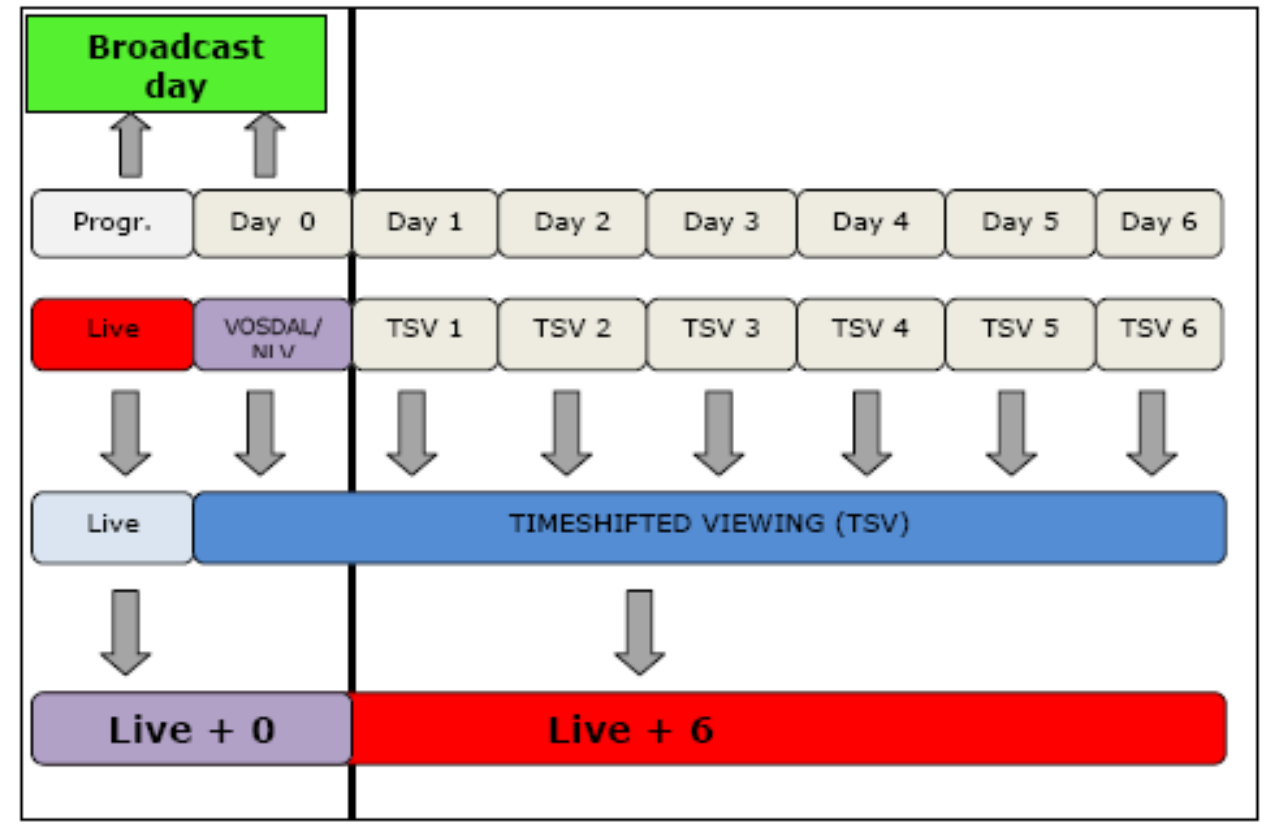

Figure 1: Relevant types of viewing behavior

Data from the live viewers, near live viewing and VOSDAL viewers are available to the market the day after the broadcast of a show (live +0 ). The final ratings are available seven days after the live data, offering additional information on the time-shifted viewers (live +6 ). Currently, there is not much difference between these numbers, as many viewers still prefer to watch a program live. This behavior will surely change over time as people get used to the technology and the entire market will have switched to digital transmissions.

Although the registration of time-shifted viewing is an important step forward in bridging the gap between the old and next generation measurement systems, this technique has several important limitations. There is still no information available regarding the use of interactive applications such as digitext, interactive advertising commercials in dedicated advertising locations, enhanced TV applications, the electronic programme guide (EPG), walled garden applications, e-mail etc. Using this kind of applications, the broadcast stream is usually replaced by a split screen application in which the live stream continues in the upper right 
corner of the application. The audio signal of the live broadcast holds a prominent place and therefore the people meter continues to register this activity as viewing behavior, although one could question the validity of this reasoning as most people focus on the interactive application and not on the live stream. None of the traditional people meters register these interactive applications.

Because of dissatisfaction with these limitations, new research methods are being tested around the world. An opportunity which was quickly seized by the telecom and cable providers, as their set-top boxes collect information on the viewing behavior of their customers. Although this technology was not developed for measurement purposes, several software adaptations can provide detailed information on viewing behavior. The British Sky Broadcasting Group (BskyB) recently established its own viewer panel using the data collected by their customers' set-top boxes. These STB's operate as people meters and register all linear and interactive television viewing behavior such as time-shifting, VOD and all kinds of interactive applications.

Belgian telecom providers are becoming increasingly interested in this type of measurement technology. As a cable dominant region most viewers switch to DVB-C, a technology with an efficient return path. The second largest provider is Belgacom TV who offers television distribution using the technology of the internet, IPTV, also providing an efficient return-path. Belgium, could therefore be an excellent test market for a next generation audience measurement system based on a set-top box approach.

\section{Empirical results: Expert users requirements}

Despite the annoyance of different actors in the field and the requirements of the current contract, the Centre for Information on Media (CIM), the Belgian trade organization in charge of audience research, has been reluctant to provide adequate solutions for the measurement of interactive applications. This conclusion is a serious bottleneck for the adoption of interactive TV advertising opportunities and is a constraining factor with regard to the development of new business models with additional revenue streams. Belgian advertisers are reluctant to invest in interactive advertising campaigns on television as long as there is no data available proving the advantage of this format compared to the classical 30 second spot. Marketing budgets are limited and choices are to be made based on objective data collected by an independent organization. When asked for a prioritization of data from the different applications e.g. VOD, time-shifting, DAL's, walled garden, etc., this seems to be of no concern to advertisers. The knowledge Belgian advertisers have on the different applications is rather limited and they do not seem to be very familiar with the concept. Most advertisers simply answer that they want all available data, preferably delivered by an independent research organization which collects and controls the data. They expect this information to be incorporated in the current contract and are reluctant to pay for it. 
In order to seize the opportunities of digital transmission technologies and turn them into a success story, broadcasters are trying to convince advertisers to test the applications. Therefore, they require test cases and well-documented examples. In order to receive data they should form an alliance with telecom operators and promote these applications together. Despite the importance of these data and the current pressure of the economical crisis, broadcasters are reluctant to invest in new measurement techniques. The current people meter based approach is already very expensive and it becomes increasingly difficult to generate funds for additional research. Broadcasters also consider the current panel approach to be too limited. The growing need for data with regard to specific target groups requires a larger panel than the current 1500 households which are part of the Belgian research panel.

Telecom operators on the other hand, are becoming more and more aware of the richness of the data they collect in their set-top boxes. By offering data on the viewing behavior of all their customers, viewing data can now be collected based on a larger number of households. Eventually, all viewers will be watching television through one of the different digital transmission models, so data on the total viewing population can be collected. Unfortunately, the data logs are currently not very user friendly and need a lot of programming before they can be commercialized. Clearly, this will not be a free service. A new business model should be developed in order to reimburse telecom providers for their efforts.

\section{Technological concepts}

As mentioned before, independent of the (hardware) solution which is used, all traditional audience measurement systems have one general concept in common: they all use a select panel group in order to map the panel's viewing behaviour to a larger group, often a whole population. In Belgium for instance, 1500 households represent a population of approximately 10 million people. Consequently, the final results of such measurement systems are largely based on the assumption that the panel members are a perfect representation for the population. Although special care is taken to have a good mix of households in the panel, it is clear that these results can never be as representative as in a scenario in which the actual viewing behaviour of the whole population is measured.

Despite the lack of fully accurate results, the panel-based approach has some obvious advantages: a select group is easier to follow (in case something goes wrong) and easier to question (in order to acquire more extensive profiles). In addition to this, the need for (expensive) hardware in traditional measurement systems, incorporates that the deployment costs of such systems are tightly coupled with the number of households in the panel. Due to the fact that analogue television requires no advanced equipment to watch television, additional hardware such as the people meter, is always required for audience measurement. Due to the broadcast nature of traditional television, the broadcast operator itself cannot deduct viewing behaviour from the data in its network.

However, with the arrival of digital television, advanced hardware, called set-top boxes (STB), are now installed at the customer premises and with the entrance of telecom providers in the television market. It is obvious, that in the digital television era, the broadcast or telecom operator could now take up the role of an audience measurement organization. But what exactly would be the advantages of this new role for a broadcast or telecom operator? Should the use of a panel completely be thrown away with no respect for current audience measurement systems? And how can a broadcast or telecom operator exactly deduct which house hold members are watching a specific programme? In this section, we describe some technical concepts of a general solution which tackles these issues. 




Figure 2: Design of a set-op-box approach for mass scale audience measurement with webcam based panel members identification.

Figure 2 describes a high-level architecture of a digital television operator (telecom or cable) that takes up the role of an audience measurement instance. Every digital viewer has installed a digital STB next to his television set in order to watch the broadcastings in digital quality. For the operator, it is very easy to install a logging client on its STB which is able to keep track of all the programmes the STB is tuned in to. When this client is implemented on top of the STB's interactive middleware layer, more advanced user interaction (e.g. VOD, timeshifting, etc.) may also be logged. This logging client will then send all its acquired data within certain periods of time to the back-end of the operator. For network performance considerations, this typically is performed at night. This process is shown in the figure by the white STB, informing the operator that that specific family was watching programmes $\mathrm{Xb}$ and Yc during Linear Broadcast (LB), that programmes Xe was recorded (PVR) and then watched twice and that programmes Yb was watched by using Time Shifted (TS) viewing. Note that a telecom operator (not a cable operator) can often also deduct this type of information by analysing the traffic on its network.

It is clear that this type of logging data only provides information on a household level, meaning that the operator cannot deduct whether someone is actually watching the television show and which members of the family are actually watching. Several traditional measurement systems focus on the viewing behaviour of all the individuals which are part of the panel group. In most of these systems, user-level monitoring requires a special effort of all panel members. Participants have to push a personal button in the beginning and in the end of each viewing session. In some cases each household member has to wear a special piece of hardware such as the Personal People Meter (PPM) which is able to perform audio based measurements but otherwise works quite similar compared to the fixed people meter. The accuracy of these traditional measurements is very dependent on the goodwill of the participants and therefore, several control mechanisms are used to keep panel members active. Despite this dependency, the profile data of each household member are very useful for advertisers in order to detect and reach their target groups.

On the contrary, the main advantages of logging the viewing behaviour on a household level over the traditional panel based measurement systems are quite obvious: 
- The magnitude of the measurements can be (depending on the number of clients) a multiple of the panel based approach, therefore, resulting in more accurate measurement results as they are based on the monitoring of a whole population instead of assumptions based on a select panel;

- As no additional hardware is required, the deployment cost for household level measurements by the operator itself are negligible compared to traditional measurement systems;

- By deploying the logging service on the STB, it is more convenient to monitor recorded or time-shifted viewing behaviour. Note that some of the more advanced traditional measurement hardware nowadays can also monitor this type of viewing behaviour;

- An often not mentioned disadvantage of traditional measurement systems, is the lack of support for less popular television channels e.g. local or niche channels. However, with the STB approach, it is very easy to monitor every channel thus providing even more accurate results and reconnecting advertisers with broadcasters who are now left out of the audience measurement systems.

Despite the advantages of a set-top box approach, the lack of identification of individual viewer behaviour remains an important threshold. Results of the expert study showed that in order to be a valuable alternative to current audience measurement technologies, the set-top box approach should at least measure what is currently being measured. Therefore, our high level architecture was extended with a panel and a low involvement solution was found. A transparent monitoring solution is proposed based on the use of a webcam which is attached to the set-top box. When the set-top box is turned on, this webcam will start to take screenshots of the living room and send the stills to the set-top box. At the set-top box, face detection and face recognition algorithms are executed on the sampled pictures, thus deducing who is watching. These actions do not require any input from the user and therefore, the efficiency of the samples is in proportion with the high efficiency level of the algorithms. In order not to interfere with the privacy of the panel, only the results of the algorithms are send to the backend of the operator. This is shown in the figure where a blue STB represents a household that is a member of the panel group. Besides the information concerning which programmes were tuned in to, this type of STB will now also send whether a male $(\mathrm{m})$ or female (f) child (ch), teenager (t) or adult (a) were watching a specific show.

At the backend, extrapolation of this data can now take place. This can be achieved by combining the information from the large scale household-level monitoring operations, the small scale individual-level panel measurements and the information that the operator has gathered from its clients e.g. sociodemographic data, purchase behaviour, media usage, etc. This data should be requested during the installation process of the set-top box for all customers. Installing cameras in the homes of all clients would be a very invasive and expensive approach and would probably not stimulate any commercial successes. Using the methodology proposed in this paper, the information collected from the panel members can be mapped to the viewing behaviour of non-panel members. Due to the combination of data more accurate and more detailed results can be reported to broadcasters, advertisers, media agencies and other stakeholders of the audience measurement market. 


\section{Conclusion}

Advanced innovations in broadcasting technologies have led to the rise of several new challenges and opportunities for all stakeholders. Commercial broadcasters e.g. suffered several losses in the advertising department. Despite these challenges, broadcasters are very hopeful to benefit from some of the opportunities for personalized and interactive communication offered by the new digital broadcasting techniques. Television has always been one of the best measurable mass media available but lately, the current audience research methodologies could not tackle the challenge of interactive digital television. In order to keep advertisers interested, it is imperative that the gap between the possibilities of iDTV and the research methodology used for audience ratings is closed. The solution possibly lies with telecom providers who are becoming more and more aware of their market power. The settop-boxes they install at their clients' premises, do not only decode the transmission system, they also log data on the viewing data. Instead of a traditional panel approach, telecom providers could log the data of all their clients offering a better statistical representativeness. This approach is also less expensive since no dedicated hardware needs to be installed. Despite these obvious advantages, this approach lacks a major input variable compared to traditional audience measurement. Telecom providers only receive information on set-top box level, not on individual viewer level as traditional people meters do. Our research focuses on scenarios in which the traditional panel approach can be combined with information derived from the detailed loggings of the set-top boxes. The match between the two data sources could provided all stakeholders with more detailed and representative data. One scenario in which face detection and face recognition algorithms based on webcam input was used, was discussed in this paper and will be, together with other similar scenario's, extensively tested in the near future.

\section{Directions for future research}

In the near future, this set-top box based measurement approach will be tested on the technical and commercial feasibility. Expert users will continue to give feedback on the measurement model as it evolves. Next to the expert users, the developed scenarios will also be tested by residential users in order to get some insight in their willingness to participate in an audience measurements panel based on set-top box logs. Is logging all viewing data not to intrusive? As panel members, how active do they wish to be? What are their attitudes towards the webcam-based approach? What about privacy issues?

It is clear that this research project is only in an early stage and that several conditions need to be tested before a working model can be launched in the marketplace. 


\section{References}

Ahonen, T. T., Moore, A. (2005), Communities dominate Brands. London: Future Text.

Bardoel, J., d'haenens, L. (2000), 'Reinventing public service broadcasting in Europe: prospects, promises and problems’, Media, Culture \& Society, 30: 337, pp. 337-355.

Brandts, K., \& De Bens, E. (2000), The status of TV broadcasting in Europe. In J. Wieten, G. Murdoch, P. Dahlgren, eds., Television across Europe. A Comparative Introduction. London: Sage Publications, 2000.

Bermejo, F. (2009), 'Audience Manufacture in the Historical Perspective: from Broadcasting to Google’, New Media \& Society, 11:1\&2, pp. 133-154.

Buzzard, K. S. (2002), 'The Peoplemeter Wars: A Case Study of Technological Innovations and Diffusion in the Ratings Industry', Journal of Media Economics, 15:4, pp. 273-291.

Cappo, J. (2005), The Future of Advertising: new media, new clients, new consumer in the post-television age, Chicago: McGraw-Hill.

Carat (2006), Media Key Facts 2006, Brussels: Aegis Media Group.

Carat (2007), Media Key Facts 2007. Brussels: Aegis Media Group.

Cauberghe, V., De Pelsmacker, P. (2006), 'Opportunities and Thresholds for Advertising on Interactive Digital TV: A View from Advertising Professionals', Journal of Interactive Advertising, 7; 1, pp. 25-40.

Dahlgren, P. (2000), Key Trends in European Television. In J. Wieten, G. Murdoch, P. Dahlgren, Eds., Television across Europe. A comparative introduction. London: Sage Publications, pp. 23-24.

De Bens, E., Mazzoleni, G. (1998), The Media in the Age of Digital Communicatio. In D. Mcquail, K. Siune, Eds., Media Policy. Convergence, Concentration \& Commerce, Londen: Euromedia Research Group, pp. 165-179.

De Bens, E., Raeymaeckers, K.(2007), De pers in België : het verhaal van de Belgische dagbladpers: gisteren, vandaag en morgen, Tielt: Lannoo.

De Marez, L., Evens, T., Schuurman, D., Berte, K., De Jonghe, E. (2007), Assessing the Added Value of Alternative Distribution Methods for Digital TV in a cable-dominant Region. In A. Urban, B. Sapio \& T. Turck, Eds., Digital Television Revisited. Linking Users, Markets and Policies. Budapest: COST Action 298.

de Vos, B., Appel, M. (2007), Is a Rating still a Rating? How Changing Behaviour alters Definitions in the Digital Age. Paper presented at the ESOMAR, Worldwide Multi Media Measurement Conference (WM3).

Doyle, G.(2002), Understanding Media Economics. Londen: Sage Publications Ltd.

Ellis, J.(2000), Seeing Things. Television in the Age of Uncentainty. London: I.B. Tauris \& Co Ltd.

Jaffe, J.(2005), Life after the 30-second spot: energize your brand with a bold mix of alternatives to traditional advertising, Hoboken: Wiley. 
Lyle, D. (2008), The Digital Revolution - What does it mean for Advertising. In G. Terzis, Ed, European Media Governance. The Brussels Dimension Bristol, Intellect Books,. pp. 121128.

McQuail, D. (1998), Western Media: The Mixed Model under Threat? In J. Downing, A. Mohammadi, A. Sreberny-mohammadi, Eds., Questioning the Media. A Critical Introduction, London: Sage Publications Ltd., pp. 147-164.

McQuail, D.(1998), Commercialization and beyond. In D. Mcquail \& K. Siune, eds., Media Policy. Convergence, Concentration \& Commerc,. London: Euromedia Research Group, pp. 107-127.

McQuail, D. (2005), Mass Communication Theory. 5th edition. London: Sage Publications. .

Musschoot, I., Lombaerts, B. (2008), Media in Beweging. Handboek voor de professional. Leuven: Lannoo Campus.

Napoli, P. M. (2001), 'The Audience Product and the New Media Environment: Implications for the Economics of Media Industries'. International Journal on Media Management, 3:2, pp. 66-73.

Negroponte, N.(1995), Being Digital. London: Cornet Books.

Nolan, D. (1997). 'Bottlenecks in Pay Television. Impact om Market Development in Europe’. Telecommunications Policy, 21: 7, pp. 597-610.

Otten, R. (2006). Achter Televisie. Omroepmarkten en -structuren in West-Europa. Antwerpen: Garant.

Peeters, A., Jagers, R., Kalfs, N. (2005), Wie kijkt? De meting achter de kijkcijfers. Amstelveen: Stichting KijkOnderzoek.

Picard, R. G. (2003), Business Issues facing New Media. In J. Servaes, Ed., The European Information Society, Bristol: Intellect.

Schultz, D. E. (2006), 'Media Synergy: the next Frontier in a Multimedia Marketplace'. Journal of Direct, Data and Digital Marketing, 8: 10, pp. 13-29.

Schultz, D. E., Pilotta, J. J., Block, M. P.: Media Consumptions and Consumer Purchasing. Connecting the Dots... finally. Paper presented at the ESOMAR Worldwide Multi Media Measurement, 2006. from http://www.bigresearch.com/esomar2006.pdf

Seabright, P., Van Hagen, J., Weeds, H. (2007), Competition and Market Power in Broadcasting: where are the rents? In P. Seabright, J. Van Hagen, Eds., The Economic Regulation of Broadcasting Markets, Cambridge: Cambridge University Press, pp. 47 - 80.

Sinclair, J. (2004), Television and the Concentration of Ownership. In J. Sinclair, G. Turner, G. ,Eds., Contemporary World Television, London: British Film Institute, pp. 1-6.

Siune, K., Hulten, O. (1998), Does Public Broadcasting have a future? In D. McQuail, K. Siune, K., Eds., Media Policy. Convergence, Concentration \& Commerce, Londen: Euromedia Research Group, pp. 23 -37.

Siune, K. (1998), Changing Media and Changing Society, In D. McQuail, K. Siune, Eds., Media Policy. Convergence, Concentration \& Commerce. London: Euromedia Research Group, pp. 1-6. 
Urban, A. (2008), Changing Business Environment in Digital Television. In A. Urban, B. Sapio, \& T. Turck, Eds., Digital Television Revisited: Linking Users, Markets and Policies. Budapest: COST Action 298.

Van Laeken, F. (1996), Even geduld a.u.b. Een testbeeld van de televisie in Vlaanderen, Antwerpen: Icarus.

Wieten, J., Murdoch, G., Dahlgren, P. (2000), Television across Europe. A comparative Introduction. London: Sage Publications.

Wilbur, K. C. (2008), 'How the Digital Video Recorder (DVR) changes Traditional Television Advertising'. Journal of Advertising, 37: 1, pp. 143-149.

\section{Biography}

Katrien Berte is a researcher and phd student at Ghent University, research Group for Media and ICT, department of Communication Sciences. Her research interest lie within media economics, interactive digital television and advertising and new media.

Philip Leroux is working as a PhD student in the Broadband Communication Networks Lab of the Department of Information Technology of the Ghent University. His main research focuses on the efficient delivery of highly interactive and personalized video services.

Lieven De Marez is research director at MICT, and teaches 'innovation research' and 'new communication technologies' at the department of Communication Sciences (Ghent University). Lieven is also part of the management team of iLab.o, IBBT's facilitating infrastructure for Living Lab research.

Els De Bens is professor emeritus at the Department of Communication Sciences at Ghent University. Her main research activities are situated in media economy, media policy, journalism studies and ICT. She is an active member of several international networks.

Filip De Turck is professor at the Department of Information Technology of the Ghent University and the IBBT. His main research activities include design and performance optimization of advanced telecommunication services and management platforms. 


\section{Intellećt tial ats}

Cultural \& Media Studies

Performing Arts

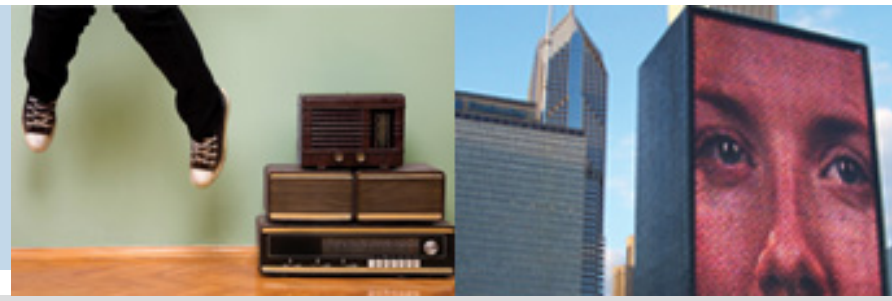

$\underline{1}$

Journals $>$ Cultural \& Media Studies $>$ International Journal of ... $\geqslant$ Volume 1 Issue 2

- Journals

Subscription info

Promotions

Free journal

issues

Electronic access

Advertise with us

Style guide

Recommend a

journal form

Open Access

Option

- Home

- Books

- Mobile apps

- Publish with us

- News

- About us

Resources for

Book authors and

editors

- Journal editors

and contributors

- Events

- Frequently Asked Questions

$\begin{array}{ll}\text { List J ournals by } & \text { Cultural \& Media Studies | Film Studies | Performing Arts | Visual Arts } \\ \end{array}$

Table of contents

\section{International J ournal of Digital Television}

\section{Subscribe to this journal \\ Call for Papers \\ Editorial \& Advisory Boards \\ Back Issues}

\section{Volume 1 Issue 2}

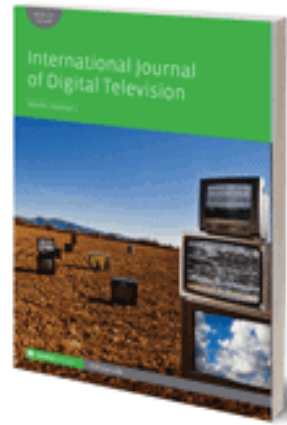

Cover Date: June 2010

Challenges and opportunities of iDTV for audience measurement systems: a set-top box-based approach

Authors: Els De Bens And Katrien Berte And Philip Leroux And Dimitri Schuurman And Lieven De Marez And Filip De Turck

DOI : 10.1386/jdtv.1.2.221_7

\section{ISSN: 20404182}

First published in 2010

3 issues per volume

\section{Keywords}

return path data, interactivity, audience measurement, iDTV,

Submit to this journal

\section{Abstract}

Advanced innovations such as digital transmission technologies and personal video-recorders (PVRs) have changed TV viewing behaviour. In order to maintain their position as the world's largest advertising channel, television broadcasters are increasingly dependent on accurate and in-depth audience data. Unfortunately, the traditional measurement techniques fail to keep up with innovations of interactive digital TV (iDTV) such as videoon-demand (VOD), time shifted viewing, an electronic programme guide (EPG), ad avoidance using the PVR, etc. This article reflects on the current state of audience measurement in Europe and describes our search to tackle some of the challenges. Contrary to traditional systems that use dedicated and expensive hardware, this article presents a set-top box-only approach.

\section{Search $\boldsymbol{\nabla}$}

enter keyword here

Advanced search >

Latest news

8th November 2011

The Soundtrack New Issue 4.1 Read more ?

2nd November 2011

International Textiles and Apparel Association conference Read more ?

31st October 2011

Call for Contributions: Directory of World Cinema: Scotland Read more ?

download

New 2012

Intellect

J ournals

Catalogue

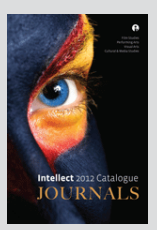

download

New 2012

Intellect

Journal

Packages

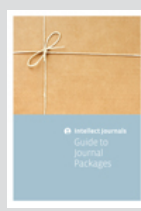

download

J ournal

Subscription

Rates: back

volumes to

2011

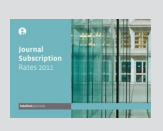

Tags:

Your tags: Please login or register if you don't have a user account. 


\section{Intellect Journals}

Keep

up-to-date with our RSS feeds

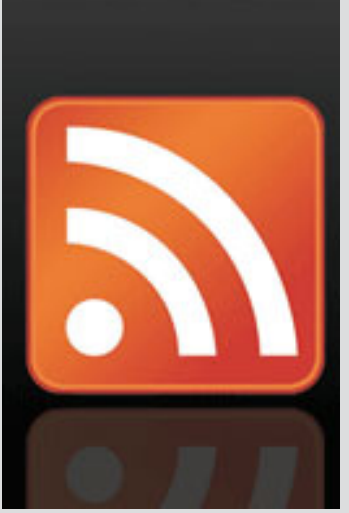

Terms \& Conditions | Site Map | Print this page | Contact us | CIntellect 2010 info@intellectbooks.com 